\title{
Assessment of different models for bathymetry calculation using SPOT multispectral images in a high-turbidity area: the mouth of the Guadiana Estuary
}

\author{
N. Sánchez-Carnero ${ }^{\mathrm{a}, \mathrm{b}_{*}}, \mathrm{~J}_{\text {. Ojeda-Zujar }}^{\mathrm{b}}$, D. Rodríguez-Pérez ${ }^{\mathrm{c}}$, and J. Marquez-Perez ${ }^{\mathrm{b}}$ \\ ${ }^{a}$ Kartenn Tecnologías para la Gestión Ambiental y Territorial, Galicia, Spain; ${ }^{b}$ Departamento de \\ Geografia Física y Análisis Geográfico Regional, Universidad de Sevilla, Sevilla, Spain; \\ ${ }^{c}$ Departamento de Física Matemática y de Fluidos, Universidad de Educación a Distancia, \\ Madrid, Spain
}

(Received 22 May 2013; accepted 31 October 2013)

\begin{abstract}
Periodic calculation of coastal bathymetries can show the evolution of geomorphological features in active areas such as mesotidal estuary mouths. Bathymetries in shallow coastal areas have been addressed mainly by two technologies, lidar and optical remote sensing. Lidar provides good accuracy, but is an expensive technique, requiring planned flights for each region and dates of interest. Optical remote sensing acquires images periodically but its results are limited by water turbidity. Here we use a lidar bathymetry to compare different bathymetry computation methods using a SPOT optical image from a nearby date. Three statistical models (green-band, PCA correlations, and GLM) were applied to obtain mathematical expressions to estimate bathymetry from that image: all gave errors lower than $1 \mathrm{~m}$ in an area with depths ranging from 0 to $6 \mathrm{~m}$. These algorithms were then applied to images from three different dates, correcting the effects caused by different tidal and atmospheric conditions. We show how this allows the study of morphological changes. We discuss the accuracy obtained with respect to the reference bathymetry $(0.9 \mathrm{~m}$ on average, but less than $0.5 \mathrm{~m}$ in low-turbidity areas), the effects of the turbidity on our estimations, and compare both with previously published results. The results show that this approach is effective and allows identification of known features of coastal dynamics, and thus it would be an important step towards short-term bathymetry monitoring based on optical satellite remote sensing.
\end{abstract}

\section{Introduction}

Coastal areas have been the subject of numerous studies in recent decades due to their economic, ecological, and social importance (Costanza and Farley 2007; Newton and Icely 2008), and their vulnerability to human pressure. Managing and preserving coastal marine resources is an essential challenge given their natural resources and the opportunities for economic development of coastal communities (Clark 1996). To accomplish sustainable management, bathymetric information constitutes a key element (Gao 2009), whether the study is focused on near-shore geomorphology (Finkl, Benedet, and Andrews 2005; Hogrefe, Wright, and Hochberg 2008), hydrology and sedimentary processes (Prandle 2006; Higgins, Jaffe, and Fuller 2007; Jaffe, Smith, and Foxgrover 2007; Klemas 2009), fishing (Nishida et al. 2001), storm and tsunami effects (Matsuyama, Walsh, and Yeh 1999), mineral exploration (Basu and Malhotra 2002), ecology (Stocks,

*Corresponding author. Email: noelas@gmail.com 
Boehlert, and Dower 2004; Wedding et al. 2008), or the development of hydrodynamic models (Irish and White 1998; van Rijn et al. 2003; Sutherland et al. 2004), just to mention some.

To obtain bathymetries under wide depth and water turbidity ranges, acoustic methods are usually employed. Multibeam echosounders provide a full bottom coverage bathymetry and also textural information. However, they are still very expensive systems and are usually mounted onboard large vessels. When multibeam echosounders are not an option, single-beam echosounders represent a compromise between quality and cost. To obtain the full bottom bathymetry, specialized methodologies have been developed that optimize surface reconstruction from single-beam bathymetric transects (Sánchez-Carnero et al. 2012).

The new lidar technology, based on laser signals, allows for rapid surveys in both large and small areas where direct surveying would be difficult, dangerous, or impossible using water-borne techniques (Guenther et al. 2000), and provides very accurate bathymetry. Despite this technology having obtained excellent results (Chust et al. 2010), its extremely high cost dissuades potential users.

Although less accurate, there is a low-cost alternative to lidar: multispectral satellite imaging. During recent decades, advances in high-resolution multi-spectral satellite imagery (SPOT, Quickbird, IKONOS, etc.) and initiatives to lower their acquisition costs for research purposes have expanded their uses. Bathymetry calculation is an example. As a result of an increase in the availability of commercially provided these images, the accuracy of water depth analysis has improved accordingly (Stumpf, Holderied, and Sinclair 2003). In clear and very shallow waters with good transparency conditions, accuracy comparisons with hydrographic data show mean errors around $10-30 \%$ (McIntyre et al. 2006), with a maximum effective depth range from 6 to $10.5 \mathrm{~m}$ (Lafon et al. 2002). The major source of error is the compounded attenuation by the atmosphere and water column on radiance reflected by the seabed and received by the satellite (Densham 2005). In high-turbidity conditions, however, attenuation in the water column becomes a greater source of error than the atmosphere.

Algorithms to determine bathymetry from optical imaging are based on relationships developed by numerous authors to determine depth from reflectance (Lyzenga 1978; Benny and Dawson 1983; Garlan 1989; Bierwirth, Lee, and Burne 1993; Maritorena 1996; Provost et al. 1999; Collet et al. 2000; Gianinetto and Lechi 2004; Lyzenga, Malinas, and Tanis 2006) using the single or quasi-single scattering theory (Gordon, Brown, and Jacobs 1975).

Lyzenga (1985) introduced a methodology for bathymetry extraction based on linear relationships derived from the Lambert-Beer equation of attenuation. This method has been used by other authors using different satellite images: Quickbird (Lyons, Phinn, and Roelfsema 2011), Worldview-2 (Doxani, Karantzalos, and Tsakiri-Strati 2012), Landsat (Liceaga-Correa and Euan-Avila 2002), etc. Lyzenga's methodology is based on the correction of sunglint effect (using the near infrared (NIR) band) and the removal of the water column. According to Lyzenga's approach, benthic habitat is assumed as a spatially variable feature responsible for seabed reflectance variability together with water depth. However, since spatial atmospheric and water column corrections are performed identically for the entire image, this theoretical approximation will fail whenever its main assumption of homogeneity (no spatial changes) in water column and atmospheric characteristics fails. Thus, bathymetric mapping will be most straightforward where water quality and atmospheric conditions are invariant over the scene. Under these conditions, both depth and an effective attenuation coefficient of the water over several 
different bottom types may be retrieved from passive, multispectral imagery. As scenes become more complex, with changing water type and variable atmospheric conditions, a straightforward multispectral image analysis will no longer be sufficient to estimate depth (Philpot 1989).

Different approaches have been applied by other authors.

(1) Band ratios. Reflectance ratios in two or more wavebands are used to determine water depth based on the difference in attenuation for different wavelengths. Depth is determined from linear or nonlinear expressions of these ratios through correlation with known values (Dierssen et al. 2003; Stumpf, Holderied, and Sinclair 2003; Bramante, Raju, and Sin 2013). These methods require the solution of fewer parameters and are less affected by changes in bottom reflectance, as both wavelengths are affected similarly by bottom albedo; they have the drawback of not having a sound physical foundation and having ad hoc parameters to be selected by the user.

(2) Adaptations of Lyzenga's linear method to a heterogeneous water column. The splitting of the water column into levels of differing attenuations (due to turbidity) would allow improvement in depth calculations. In order to find this, splitting adaptive algorithms have been used such as the stratified genetic algorithm (Gianinetto and Lechi 2004).

(3) Homogeneous regions classification algorithms. The division of the study area into homogeneous areas (with the same bottom or turbidity types) helps improve depth calculation. Hierarchical Markov chain algorithms have been used for this (Provost et al. 1999, 2004).

The aim of this work is to assess the use of SPOT images as sources of bathymetric data in the turbid waters of the Guadiana estuary (Huelva, Spain). The results will be calibrated and groundtruthed with respect to lidar data acquired at a date close to the image. We will also explore the possibility of using the historical archive of SPOT images to gain information about morphological evolution of the submarine delta, complementing lidar bathymetric data (with high resolution but without periodic possibilities).

\section{Study area}

The study area is the Guadiana estuary delta, in the westernmost area of the Andalusian coast, southern Spain $\left(37^{\circ} 10^{\prime} \mathrm{N}, 7^{\circ} 23^{\prime} \mathrm{W}\right)$, which forms the border with Portugal (Figure 1). This estuary mouth has a slightly triangular shape, about $15 \mathrm{~km}$ wide at its maximum in the $\mathrm{E}-\mathrm{W}$ axis and $5 \mathrm{~km}$ at its $\mathrm{N}-\mathrm{S}$ axis.

In this area, wave motion is a dominant westerly that forces a clear easterly longshore drift, although occasionally eastern storms occur. The tidal spring range in the area can reach $3.4 \mathrm{~m}$, originating an important mesotidal dynamic behaviour in the mouth estuary.

Regarding geological characteristics (Morales 1997), it is a large sedimentary area consisting of a succession of barrier islands and tidal marshes. These sedimentary features are formed from sediments carried mainly by the Guadiana River and, to a lesser degree, by sediments transported by the easterly dominant longshore drift from Portuguese beaches (Figure 1).

Major changes in the shoreline and submarine delta in the system of barrier islands and tidal marshes have been observed since the 1970s (González, Dias, and Ferreira 2001). This is an area with constant geomorphological changes caused by the high 


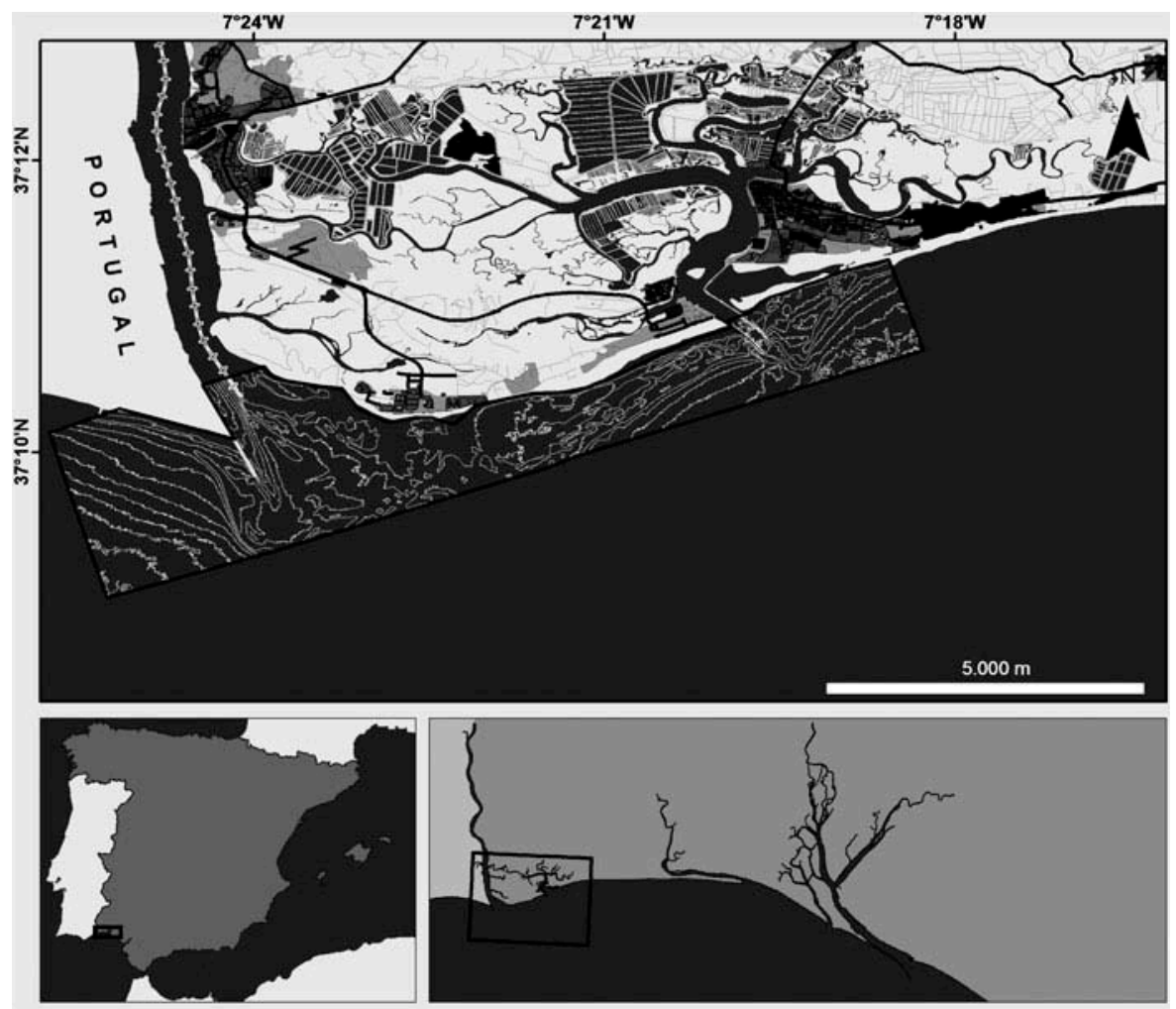

Figure 1. Study area. Black line shows the area covered by LiDAR sensor. Bathymetric lines are also shown. Polygon outlined with dashed line defines the low-turbidity area.

accretion rate which formed barrier islands over centuries. These phenomena have created the anthropological activities in this estuary and the associated submarine delta (dikes, etc.).

\section{Material and methods}

\section{Physical principles for bathymetry calculation from satellite images}

The basic premise behind water depth calculations is that the radiance received by the satellite is a function of five parameters: (1) incoming solar radiation; (2) attenuation of radiation into and out of the atmosphere; (3) attenuation of radiation into and out of the water column; (4) reflectance properties of the seabed; and (5) depth of water (Densham 2005). Thus, the depth of water can be resolved by finding values for the first four parameters (Lyzenga, Malinas, and Tanis 2006).

Bathymetry calculation from satellite images requires consideration of a number of physical assumptions about these processes.

First, a stable calibration of the sensor is required to obtain top of the atmosphere (TOA) radiance values from digital numbers in the images using a simple linear relationship between both. Second, a good atmospheric correction is required which removes the effects of atmospheric scattering in each band and compensates atmospheric absorption, commonly also using a simple linear relationship between TOA and water leaving 
radiances; the same correction must be applied to the sun incident radiance, in order to know water solar irradiance and calculate reflectance (which is assumed to be a parameter independent of acquisition conditions). All these corrections in combination amount to a linear expression of the spectral band values $b_{\lambda}$ to obtain band reflectance $\rho_{\lambda}$ :

$$
\rho_{\lambda}=R_{\lambda} b_{\lambda}-S_{\lambda}
$$

where $S_{\lambda}$ and $R_{\lambda}$ are band- and scene-specific coefficients, respectively.

This water reflectance is the sum of three effects: water surface specular reflection (or sunglint, which is assumed to be almost the same for all optical bands, as it mostly depends on water surface roughness), water column scattering, and bottom reflection. Fortunately, NIR bands can be assumed to provide only the first term, so that all the others can be corrected from this effect; in fact, all other reflectance contributions being constant, sunglint can be characterized for each band from its statistical comparison with respect to the NIR band through the coefficient

$$
K_{\lambda}^{N I R}=\frac{\operatorname{Cov}\left(\rho_{\lambda} \rho_{N I R}\right)}{\operatorname{Var}\left(\rho_{N I R}\right)}=\frac{\rho_{\lambda} \rho_{N I R}-\rho_{\lambda} \rho_{N I R}}{\rho_{N I R}^{2}-\rho_{N I R}^{2}},
$$

where Cov and Var denote covariance and variance, respectively, in respective reflectance values in the given homogeneous area and $x$ average value of variable $x$ in the chosen area. Thus sunglint correction is performed as (Lyzenga, Malinas, and Tanis 2006):

$$
\hat{\rho}_{\lambda}=\rho_{\lambda}-K_{\lambda}^{N I R}\left(\rho_{N I R}-\rho_{N I R}\right),
$$

being $\hat{\rho}_{\lambda}$ the estimated reflectance contributed only from water column scattering and sea bottom reflection.

Finally, this sunglint corrected seabed and water column reflectance is shown to be (Maritorena, Morel, and Gentili 1994)

$$
\hat{\rho}_{\lambda}=\rho_{w \lambda}+\left(\rho_{s \lambda}-\rho_{w \lambda}\right) \exp \left(-k_{\lambda} d\right)
$$

where $\rho_{w \lambda}$ is the sunglint-corrected reflectance from an infinitely deep water column (of the same characteristics), $\rho_{s \lambda}$ is the bottom sediment reflectance (for an infinitely thin water column), $k_{\lambda}$ denotes water total attenuation coefficient, and $d$ is water column depth. The assumption usually made here is that these coefficients are constant along the study area or, at least, constant over the region of interest within it. Applying logarithms, a linear relationship between depth and band reflectance values is obtained:

$$
\log \left(\hat{\rho}_{\lambda}-\rho_{w \lambda}\right)=\log \left(\rho_{s \lambda}-\rho_{w \lambda}\right)-2 k_{\lambda} d(x, y) .
$$

$\rho_{w \lambda}$ can be computed as the average value of $\hat{\rho}_{\lambda}$ in a deep-water area; however, the other two coefficients $\left(\rho_{s \lambda}-\rho_{w \lambda}\right)$ and $k_{\lambda}$ require calibration with known bathymetric information.

It is noteworthy that due to all relationships considered being linear, all previous expressions, from Equation (2) onwards (that were given in terms of band reflectances), can be straightforwardly written in terms of band digital values, keeping almost the same algebraic form, using Equation (1). The only difference will be a former transformation of 
the digital numbers $b_{\lambda}$ to remove the shift in TOA radiance caused by atmospheric aerosol (namely the term $S_{\lambda} / R_{\lambda}$ in Equation (1)).

\section{Satellite images and LiDAR DEM}

One SPOT-5 HRG multispectral mode image was used (obtained through the Remote Sensing National Programme of Spain, Plan Nacional de Teledetección), acquired on 6 August 2011. The image has four spectral bands (green, 500-590 nm; red, 610-680 nm; near-infrared, 780-890 nm; short-wave infrared, 1580-1750 nm), all with spatial resolution of $10 \mathrm{~m}$. The image scene has less than $25 \%$ cloud cover. Geometrical correction was provided by AMAA, ${ }^{1}$ using nearest-neighbour interpolation (Figure 2). Data from a lidar flight acquired with a Hawk Eye II bathymetric sensor were employed as bathymetry reference data for the study area (Figure 2). The flight was on 23 June 2011. The Hawk Eye II sensor gathers both bathymetric depths and topographic elevations in the same coordinate framework in one mission. Vertical resolution for bathymetric measurements was assessed between 32 and $62 \mathrm{~cm}$ in sedimentary bottoms by Chust et al. (2009). After classification of the original LAS point cloud, the lidar bathymetric data were assembled as a raster digital terrain model (DTM) with $2 \mathrm{~m}$ of spatial resolution.

Three other SPOT images, from the same source and with the same corrections and similar characteristics (number of bands, spatial resolution, scene cloud cover) were also used. Their acquisition dates were 30 September 2008, 3 August 2009, and 15 July $2012,{ }^{2}$ i.e. approximately corresponding to the same season as the 2011 image. These images were intended to study the potential to assess bathymetry changes over the years in this area.

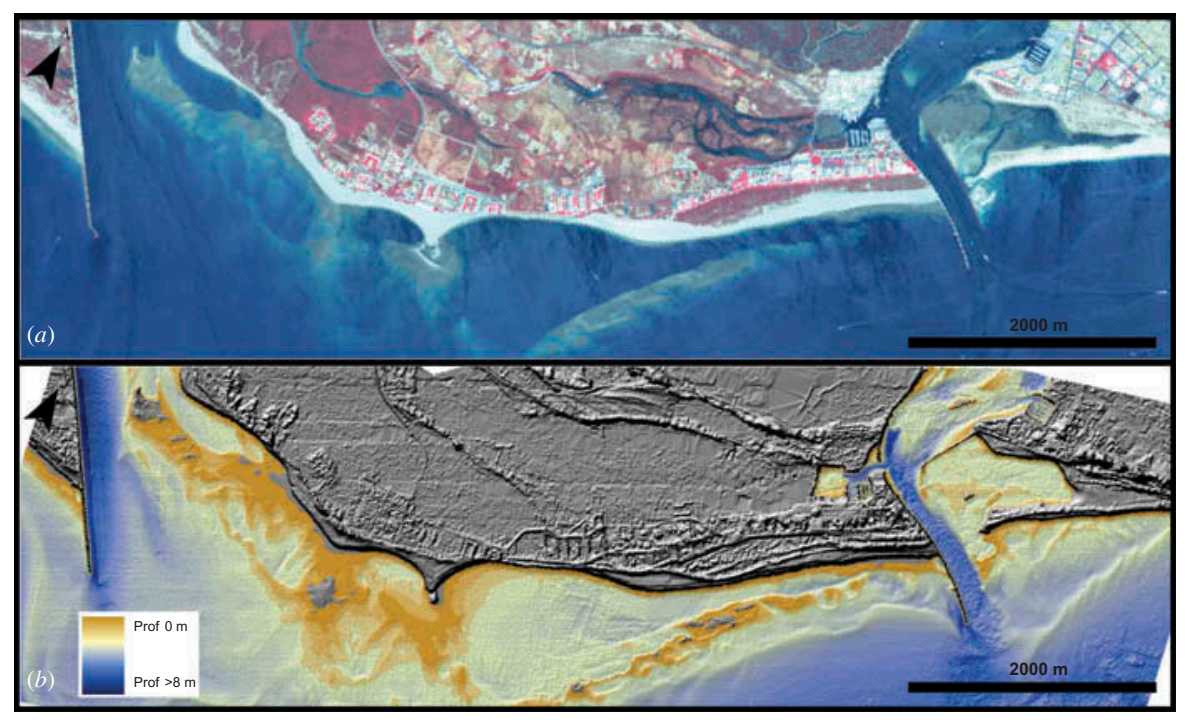

Figure 2. (a) 3,2,1-band combination of the 2011 SPOT image; (b) lidar-derived digital terrain model (DTM). 


\section{Satellite image processing}

All SPOT images were processed using ESA's BEAM open source software, ${ }^{3}$ with custom macros programmed to compute statistics and apply mathematical pixelwise transforms.

For each image, sunglint effect was corrected following Lyzenga, Malinas, and Tanis (2006). A region of interest (ROI) was defined in a deep-water area where sunglint effect will dominate the relationship between the NIR band and the rest of the bands in the image. Band digital number-based $K_{\lambda}^{N I R}$ coefficients were calculated in the ROI applying Equation (2) to the green and red SPOT bands, and corrected $\hat{b}_{\lambda}$ bands were computed as

$$
\hat{b}_{\lambda}=b_{\lambda}-\left[b_{\lambda}+K_{\lambda}^{N I R} \times\left(b_{N I R}-b_{N I R}\right)\right],
$$

where $b_{\lambda}$ is the ROI-averaged band value. With this correction, sunglint-corrected bands were obtained with the water column reflectance removed, i.e. where values in deep waters are near zero in all scenes (this is the only difference with respect to Equation (3) above). In fact, each value $\hat{b}_{\lambda}$ would correspond to the second term, with the exponential, on the right hand side of Equation (4). Thus, taking logarithms of these $\hat{b}_{\lambda}$ values, a new value $z_{\lambda}$ is obtained, linearly related to actual depth. However, this relationship should not be expected to hold straightforwardly in a turbid area such as the Guadiana's plume, and nonlinear corrections to Equation (5) should be considered.

\section{Statistical approaches}

Three statistical approaches - band correlation, principal component (PC) correlation, and generalized linear model (GLM) - were used to find relations between corrected bands and depth values. Data from the 2011 image were used to adjust the models; although this image time lag was barely 1 month with respect to the lidar data, no relevant changes in the delta geomorphology are expected.

Values from DTM and sunglint-corrected SPOT bands were extracted at the same locations defined as the centre of the SPOT image pixels. Pairs of corrected band digital numbers vs DTM depth were then used to adjust models.

(1) Band correlation model. Depth $Y$ was fitted with respect to sunglint-corrected green band $\hat{b}_{G}$ using a nonlinear third order polynomial of the form

$$
Y=\beta_{0}+\beta_{1} \hat{b}_{G}+\beta_{2} \hat{b}_{G}^{2}+\beta_{3} \hat{b}_{G}^{3}
$$

Only points with depth values shallower than $10 \mathrm{~m}$ according to the DTM were included to fit the model, although below $6 \mathrm{~m}$ depth, green band values showed higher dispersion.

(2) PCA correlation model. PC analysis (PCA) computes the orthogonal transformation that maintains most of the variability, reducing the number of variables. In our case, PCA is expected to keep variability caused by depth variations, disregarding smaller variations caused by local changes in turbidity, bottom type, etc. We used PCA calculated not only with corrected green and red bands $\left(\hat{b}_{G}, \hat{b}_{R}\right)$, but also with their logarithm transforms $\left(z_{G}\right.$ and $\left.z_{R}\right)$. The resulting first component $P_{1}$ 
(concentrating $91 \%$ of the variance) was used to adjust a nonlinear expression of the form

$$
Y=\beta_{0}+\beta_{1} P_{1}+\beta_{2} P_{1}^{2}+\beta_{3} P_{1}^{3}
$$

As before, only points with depths shallower than $10 \mathrm{~m}$ were used in the fit.

(3) GLM. A GLM describes a response random variable, $Y$ (depth), in terms of a linear combination of many (non-random) explanatory variables, $X_{i}$ (corrected bands and their logarithms) and possibly their product combinations, $\left(X_{i} X_{j}\right.$, etc.). It fits a nonlinear function of the mean of the observed variable, $g[\mu(Y)]$ the link function, to a linear predictor of the explanatory variables, taking into account the statistical distribution of both types of variables, such that

$$
g[\mu(Y)]=\beta_{0}+\sum_{i} \beta_{i} X_{i}+\sum_{i j} \beta_{i j} X_{i} X_{j}
$$

The set of all possible models of the form given by (Equation (4)) was generated with 'all possible' variable combinations, and their statistical deviances were evaluated. Finally, the Akaike Information Criterion (AIC) (Akaike 1974) was used to choose the best model.

For the green band and PC correlation models, depth values corresponding to the same green band value were averaged in order to obtain a mean depth value per band value; this was performed dividing the range of digital numbers in the study area into 20 equally spaced intervals (almost one interval per digital number in the range spanned by the green band). For the GLM model, raw values were used. All statistical operations were carried out using $R$. $^{4}$

The three models adjusted from the August 2011 SPOT image were applied to transform the image into estimated bathymetry layers. In order to statistically characterize the accuracy of the estimation, root mean square (r.m.s.) errors were computed for intervals of the estimated depth.

\section{Bathymetry extrapolation}

As tide level and water conditions are expected to change from one day to another, fitted models for one date cannot be used for a different one. However, at least theoretically (according to Equation (5)), depths computed by applying models derived from the 2011 image to images from other dates should be linearly related to actual depths on those dates.

In order to assess this, images acquired in 2008, 2009, and 2012 were sunglint corrected. Then their band histograms were shifted such that, over the study region, their median values were the same as in the 2011 reference image. The transformation for each band was

$$
\hat{b}_{\lambda} \leftarrow \hat{b}_{\lambda}+\operatorname{median}_{R O I}\left(\hat{b}_{\lambda}\right)+\operatorname{median}_{R O I}\left(\hat{b}_{\lambda}^{2011}\right) .
$$


This correction would account for variations in coastal aerosols over the scene on different dates, as the deep-water region used to correct sunglint is far from the coast.

Then, the same 2011 algoritms were applied. To adjust the distribution of depths estimated from those images to the 2011 depth distribution, a linear transformation was computed using the points simultaneously available from both dates (the 2011 reference and the date to be calibrated). This transformation is such that if the mean and typical deviation of the estimated depth distribution in 2011 are $Y_{2011}$ and $\sigma_{Y 2011}$, respectively, and the corresponding values for another image are $Y$ and $\sigma_{Y}$, the adjusted bathymetry $Y^{\prime}$ will be computed as

$$
Y^{\prime}=\frac{\sigma_{Y 2011}}{\sigma_{Y}}(Y-Y)+Y_{2011}
$$

According to Equation (5), the gain of this linear transformation would account for changes in the water column optical diffusion coefficient, $k_{\lambda}$, while the bias would account for changes in water optical thickness (i.e. tide height).

\section{Results}

\section{Depth correlation models}

Green band and PCA correlation methods provided third degree polynomial adjustments, given by

$$
Y=-7.29+0.569 \hat{b}_{G}-0.00788 \hat{b}_{G}^{2}-0.00113 \hat{b}_{G}^{3}
$$

and

$$
Y=-2.85-0.349 P_{1}-0.0165 P_{1}^{2}-0.000188 P_{1}^{3},
$$

with $r^{2}$ values of 0.989 and 0.991 , respectively (Figure 3).

Bands $\hat{b}_{G}$ and $\hat{b}_{R}$ had the biggest contributions to the first PC, with loadings of 0.773 and 0.602 , respectively; the contributions of $z_{G}$ and $z_{R}$ were much lower $(0.183$ and 0.086 , respectively).

In regard to GLM, the best fitting model, according to AIC, was the one taking into account linear combinations of all variables (with significances $<0.001$ ):

$$
\begin{aligned}
Y= & -8.83+2.04 \hat{b}_{G}-2.44 z_{G}+0.576 \hat{b}_{R}-0.0377 z_{R}-0.0225 \hat{b}_{G} \hat{b}_{R} \\
& -0.353 \hat{b}_{G} z_{G}+0.0533 \hat{b}_{R} z_{R}-0.135 \hat{b}_{G} z_{R}-0.106 \hat{b}_{R} z_{G}+0.312 z_{G} z_{R} .
\end{aligned}
$$

\section{Obtained bathymetry}

Three bathymetric surfaces were calculated from the 2011 image, one for each model (Figure 4). No significant differences are visually apparent between them. The main subtidal structures (sediment accumulation zones, deeper areas, etc.) in the lidar image (Figure 2) are observable in the three bathymetries, also matching the patterns observed. On the other hand, the effect of turbidity in the Carreras River plume (the smaller river to 

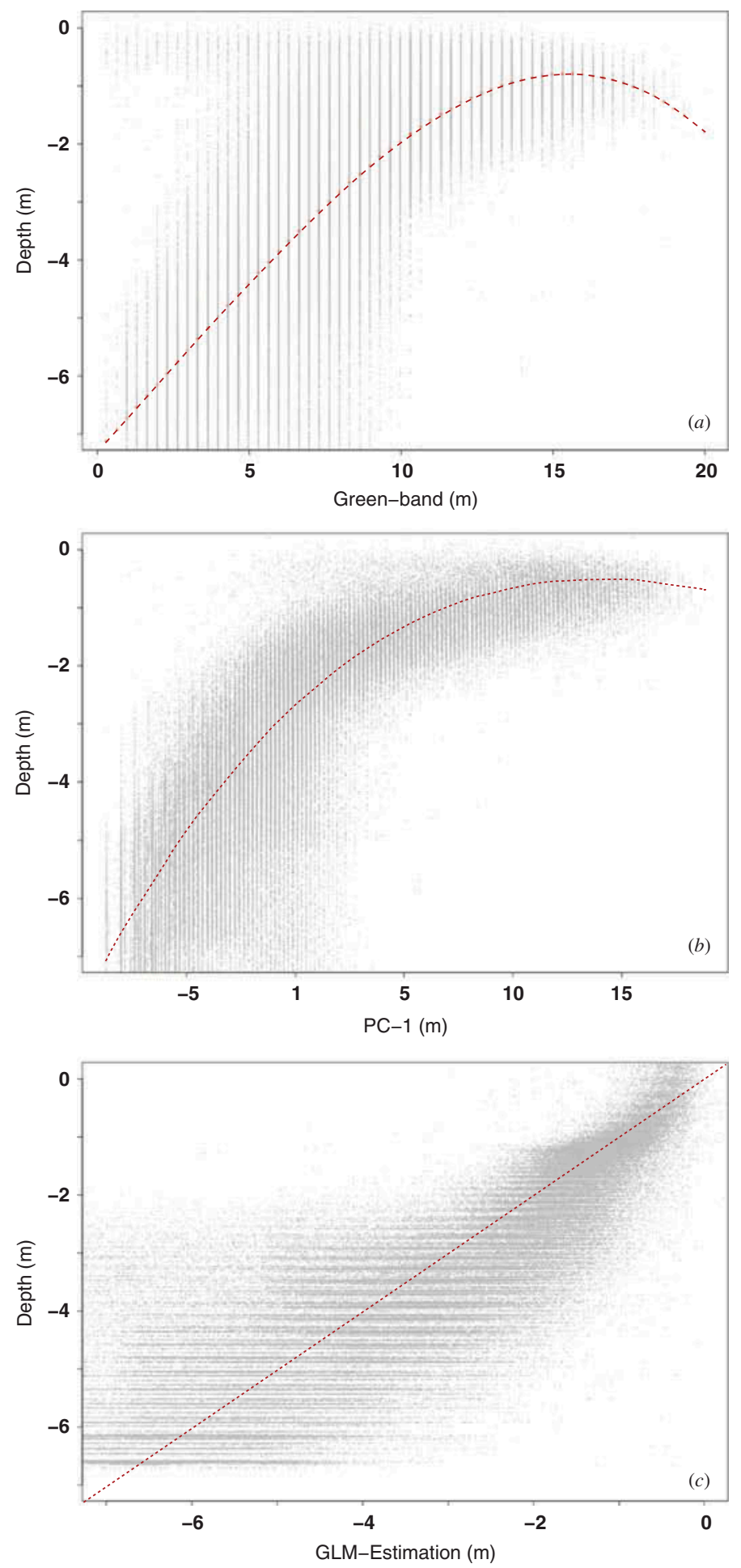

Figure 3. Fitted models for the three statistical approaches: $(a)$ green-band correlation, $(b)$ PCA correlation, (c) GLM. Actual values are represented as grey dots (the effect of digital numbers in the original images is visible). Red lines represent the fitted continuous model. 

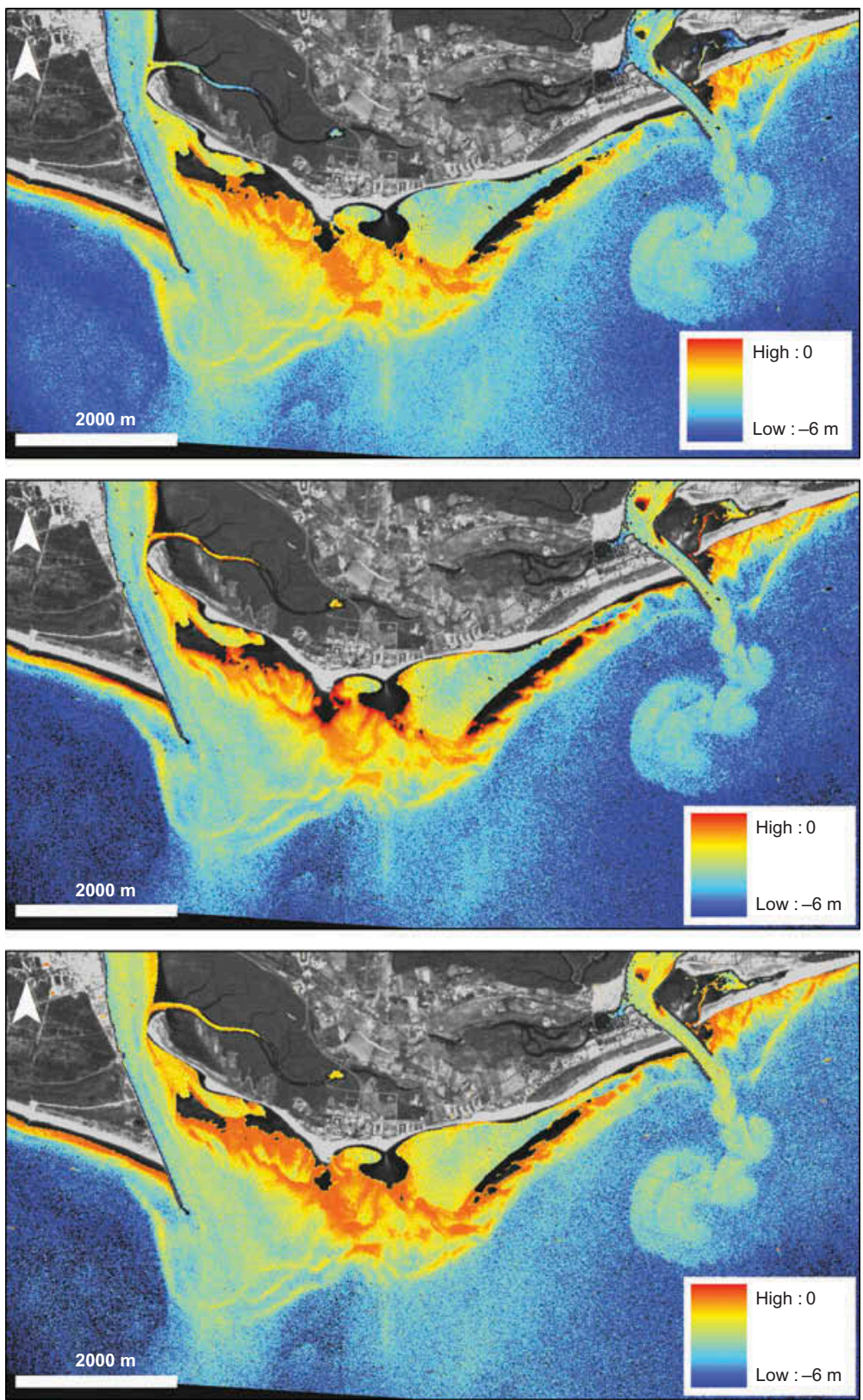

Figure 4. Bathymetries of the study area estimated from the 2011 image obtained with the greenband model (top), PCA model (middle), and GLM model (bottom).

the east of the scene) can be seen, 'confusing the algorithm's' ability to determine the bathymetry.

Errors were computed taking into account the depth range between 0 and $6 \mathrm{~m}$ and considering the $5 \%$ worst fitting points as outliers (Table 1). This range was chosen because models saturate at about $7 \mathrm{~m}$ depth in the study area, and thus estimated depths below $6 \mathrm{~m}$ cannot be trusted. According to these data, GLM provided the best fit $(0.88 \mathrm{~m})$, 
Table 1. Root mean square errors (in metres) of the bathymetric surfaces estimated from the 2011 SPOT image with respect to the 2011 DTM. Values were computed using the best $95 \%$ adjusted points in the global area and in the low-turbidity area of the image (see Figure 6).

\begin{tabular}{llccc}
\hline & & Green-band & PCA & GLM \\
\hline Global area & $0-2 \mathrm{~m}$ & 0.55 & 0.43 & 0.38 \\
& $2-4 \mathrm{~m}$ & 1.06 & 0.92 & 0.91 \\
& $4-6 \mathrm{~m}$ & 1.22 & 1.15 & 1.10 \\
No-turbid area & Global & $\mathbf{1 . 0 2}$ & $\mathbf{0 . 8 9}$ & $\mathbf{0 . 8 8}$ \\
& $0-2 \mathrm{~m}$ & 0.44 & 0.35 & 0.33 \\
& $2-4 \mathrm{~m}$ & 0.55 & 0.53 & 0.58 \\
& $4-6 \mathrm{~m}$ & 0.81 & 0.76 & 0.87 \\
& Global & $\mathbf{0 . 5 0}$ & $\mathbf{0 . 4 6}$ & $\mathbf{0 . 5 0}$ \\
\hline
\end{tabular}

slightly lower than those ones obtained with PCA and the green band (0.89 and $1.02 \mathrm{~m}$, respectively).

Observing the error distribution with depth, deeper intervals were associated with larger fitting errors, with higher variability (Table 1 and Figure 5). In Figure 5 we can observe that best fits correspond to the first few metres, especially at $0-3 \mathrm{~m}$. As shown in Figure 6, larger differences between model prediction and groundtruthing are located in the deeper area of the river channel and the westernmost area.

An area with low values of turbidity (Figure 6) was chosen to evaluate the accuracy of the adjustment obtained when assessing depth in areas with more clear waters. This area includes depths between 0 and $4.5 \mathrm{~m}$. Errors obtained with respect to the DTM (Table 2) show a reduction of $38 \mathrm{~cm}$ in the GLM r.m.s. error with respect to the entire area $(43 \%$ decrease with respect errors in Table 1). The highest improvement obtained is with the green-band method $(52 \mathrm{~cm})$, yielding 51\% lower. On the other hand, the PCA adjustment showed just a small improvement $(21 \mathrm{~cm})$, although it is still significant.

\section{Extrapolated bathymetries}

The bathymetries estimated for 2008, 2009, and 2012 using the GLM model, and with depths stretched to match the 2011 mean depth and standard deviation, showed visually the same bathymetry distribution along the study area (except for 2008; this image presents some haze in the coastal area and limits where bathymetry can be computed by our method). In order to highlight changes in bathymetries from one date to another, differences were computed between estimations from successive images (see Figure 7). The differences show areas where persistent increase in height (in orange-red tones) denotes accretion, while other areas remain quite stable during the study period (in cyangreen tones). There are, however, many areas whose estimated bottoms rise or reduce alternatively.

\section{Discussion}

We have presented the results of the application of several bathymetry estimation algorithms to SPOT images of the Guadiana estuary. To find similar results in remote sensing literature is not an easy task, since most of the papers published on bathymetry calculation were carried out in clear waters; with both multispectral (Conger et al. 2006; 

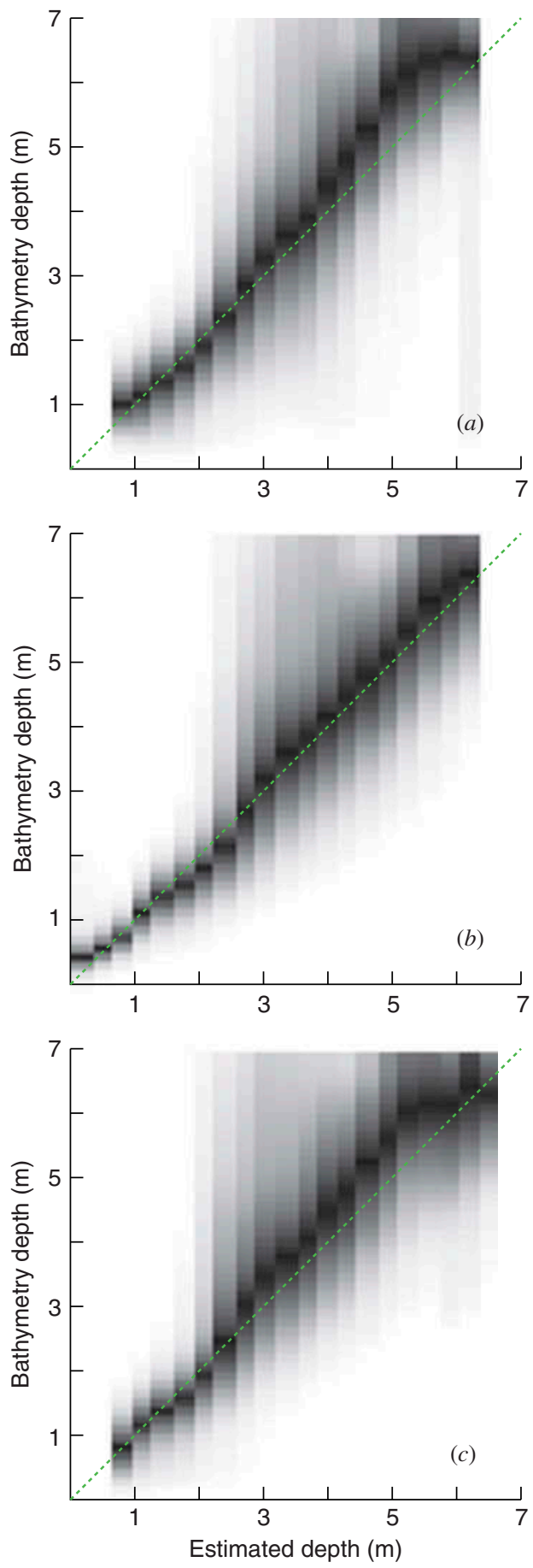

Figure 5. Comparison of estimated depths with respect to actual bathymetry. Grey tones indicate the density of points at a depth interval estimated from the images: the darker, the greater number of points having an estimated depth ( $X$-axis) are found at the given groundtruthing depth ( $Y$-axis). $(a)$ Green band correlation, (b) PCA correlation, (c) GLM. 
Table 2. Root mean square distances (in metres) of the bathymetric surfaces estimated from the 2008, 2009, and 2012 images to the 2011 DTM. Values were computed using the best $95 \%$ adjusted points.

\begin{tabular}{llcr}
\hline & & Green-band & GLM \\
\hline Image 2008 & $0-2 \mathrm{~m}$ & 0.89 & 1.15 \\
& $2-4 \mathrm{~m}$ & 1.07 & 1.25 \\
& $4-6 \mathrm{~m}$ & 1.03 & 1.67 \\
Image 2009 & Global & $\mathbf{1 . 0 2}$ & $\mathbf{1 . 4 0}$ \\
& $0-2 \mathrm{~m}$ & 0.64 & 0.66 \\
& $2-4 \mathrm{~m}$ & 1.09 & 1.08 \\
Image 2012 & $4-6 \mathrm{~m}$ & 1.14 & 1.14 \\
& Global & $\mathbf{1 . 0 2}$ & $\mathbf{1 . 0 1}$ \\
& $0-2 \mathrm{~m}$ & 0.60 & 0.60 \\
& $2-4 \mathrm{~m}$ & 0.98 & 0.92 \\
& 4-6 m & 1.27 & 1.25 \\
& Global & $\mathbf{1 . 0 1}$ & $\mathbf{0 . 9 8}$ \\
\hline
\end{tabular}

problem posed by turbidity with higher spatial and spectral resolution, using hyperspectral images (Bagheri, Stein, and Dios 1998; Lee et al. 1999). Despite resolution improvements, these works obtained results that differ markedly from studies performed in clear waters.

In our results for turbid waters, the simplest approach (the green band correlation model) presents the worst results: global r.m.s. error of $1 \mathrm{~m}$ for depth range 0-6 m. The other two more involved methods render a global r.m.s. error of $0.9 \mathrm{~m}$. The single band approach fits a model using only one optical band, so spatial variations in water column attenuation will affect the results more than in the other cases. In particular, the PCA approach seeks the best combination of highly correlated bands (and their logarithms) in order to build a variable that captures most of the variability in the area, which is expected to originate from the bathymetry. The GLM model, on the other hand, attempts to find a linear dependence on the variables and products of variables, i.e. tries to model the cross-effects of one band on the other (and their logarithms) in order to correct a linear expression for depth estimation. However, accuracy of the single band model is markedly improved in the low-turbidity area we chose at the river mouth, with r.m.s. errors around $0.5 \mathrm{~m}$ for the three methods. It should be noted that the depth range in this area is $0-4.5 \mathrm{~m}$, approximately half that considered for the global statistics (what maintains the relative error around $15 \%$ in this area).

In order to compare these errors with reported accuracies in the bibliography, we must focus on depth range of the study area, pixel size of the image, water quality, availability of in situ data, etc. Recently, Bramante, Raju, and Sin (2013) tested three different methods of bathymetry calculation in turbid waters using $2 \mathrm{~m}$ pixel images, obtaining r.m.s. between 0.48 and $0.64 \mathrm{~m}$ in an area $0-4 \mathrm{~m}$ deep (i.e. 12-16\%). With similar characteristics, $2.5 \mathrm{~m}$ pixel size and 0-8 $\mathrm{m}$ depth, Densham (2005) tested three methods for bathymetry calculation and obtained errors between $11 \%$ and $16 \%$. Lee et al. (1999) used a theoretical approach to determine water optical apparent properties and obtained worse results in turbid waters $(\sim 11 \%)$. In an attempt to asses a low-cost option, Zhang, Gao, and Gu (2011) evaluated the possibility of using MODIS images (freely available) for bathymetry calculation in turbid waters. The r.m.s. obtained in this work was very good $(2 \mathrm{~m})$ taking into account the spatial resolution, although the 

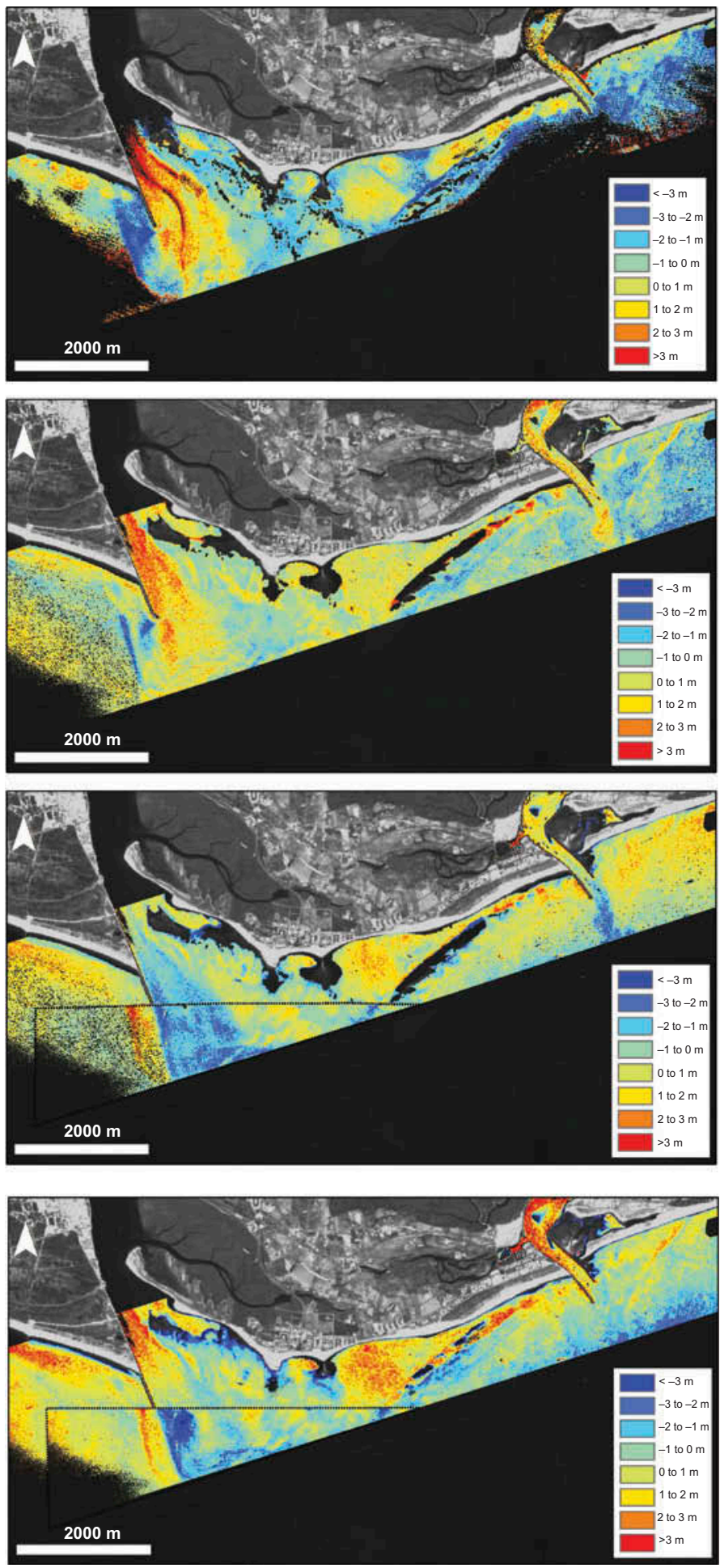

Figure 7. Bathymetry differences computed between bathymetries on successive dates. Top to bottom: 2008-2009, 2009-2011, 2011-2012, and 2009-2012. Red tones indicate elevation of the sea bottom from one date to the next; blue tones indicate depression. The dashed lines in 2011-2012 and 2009-2012 images enclose the area of the artifact corrected. 
study presented a flat and homogeneous bottom. In this context, our results with an average r.m.s. error around $0.9 \mathrm{~m}$ in turbid areas, considering the depth range $0-6 \mathrm{~m}$ $(15 \%)$, are comparable with these works (our r.m.s. error in the range $0-4 \mathrm{~m}$ is $0.76 \mathrm{~m})$.

\section{Bathymetry extrapolation}

When coastal areas have high geomorphologic activity, periodic monitoring is an important issue. This monitoring provides data on the processes that are driving coastal dynamics and allows getting ahead of their consequences. Bathymetric lidar gives very accurate data (although turbidity poses also a depth limitation) but its costs may be prohibitively high, while satellite imagery is more easily available and cost effective (Mumby et al. 1999). This is the motivation of our extrapolation technique to extend lidar-calibrated models to different dates.

In Table 2, we summarize the distances of the extrapolated bathymetries to the 2011 lidar DTM. When compared with Table 1 (errors in bathymetry estimation from the 2011 image), one feature shows up: the constant global r.m.s. of the green band correlation model ( $1 \mathrm{~m}$ for all years). In fact, the GLM model also shows this feature, but not the 2008 image, which has the haze problems pointed out in footnote 2 . This means that the overall bathymetry in the study area is well fitted by the extrapolated bathymetries. Two effects can explain this observation: (1) the 2008, 2009, and 2012 scenes were acquired during high tides, so turbidity contributed by the river was lower than in the 2011 scene, acquired during low tide (when river inputs are highest); and (2) these scenes (despite the defects in the 2008 image) present fewer wind-driven waves on the sea surface than the 2011 image.

There is, however a caveat: the meaning of Equation (11). Although its physical meaning would correspond to a compensation of the $k_{\lambda}$ and tide height in Equation (5), the results do not show this dependence on tide height. The tide heights in the successive images are $2.0 \mathrm{~m}$ (2008), $2.77 \mathrm{~m}$ (2009), $1.42 \mathrm{~m}$ (2011), and $2.72 \mathrm{~m}$ (2012). However the differences between $Y$ and $Y_{2011}$ remain around $10 \mathrm{~cm}$ except for the 2008 image, where it was $90 \mathrm{~cm}$. Thus, Equation (11) must be taken only as a convenient transformation of the estimated bathymetry to fit the global bathymetry of the area.

When using this transform to study change detection, we are taking a similar approach to other statistical methods based on the assumption of a null hypothesis (that depth distribution remains the same, or at least, its first two moments) and then testing for significant differences. In fact, this linear transformation would not account for a uniform sedimentation over the entire area, and is only intended to detect small-scale changes over sandy areas such as the study area, i.e. with no changes in its bottom type. Also river plumes, with very high turbidity cannot be handled by the method (in fact, the 2011 image is not well calibrated with respect to lidar over the Corrientes River plume) and a visual inspection is required to avoid these areas. Despite all these considerations, it becomes apparent from Figures 6 and 7 how sandy features linked to the submarine delta have been changing in the 4 year lap moving towards the shoreline.

This area of the coast is very dynamic, because it is under the hydrodynamic impact of the Atlantic Ocean: ocean waves and coastal alignment produce a strong dominant littoral drift which moves sediments eastward (Ojeda et al. 2002).

Since their construction in the 1970s, the jetties have acted as barriers to long-shore sediment transport. To the west of the dike, the eastward drift has built up two sand banks parallel to it, which are extended to the south in front of the delta. The motion of this bar is 
apparent in the 2009-2012 image (Figure 7) as a pair of blue-red parallel bands, denoting the zones where that bar was located in 2009 (blue) and the zone where it moved in 2012 (red).

Between the two river outlets there is a ridge of dunes that plays an important role in maintaining the morphodynamic equilibrium of beaches, serving also as a natural dike. These dunes associated with the delta platform evolve, since the construction of the jetties, migrating the sandbars northwards. This migration is aparent from the bathymetry images and also from the change series of Figure 7, where yellow and red tones (accretion areas) get closer and closer to the coast (the largest change can be observed in the 2009-2012 image).
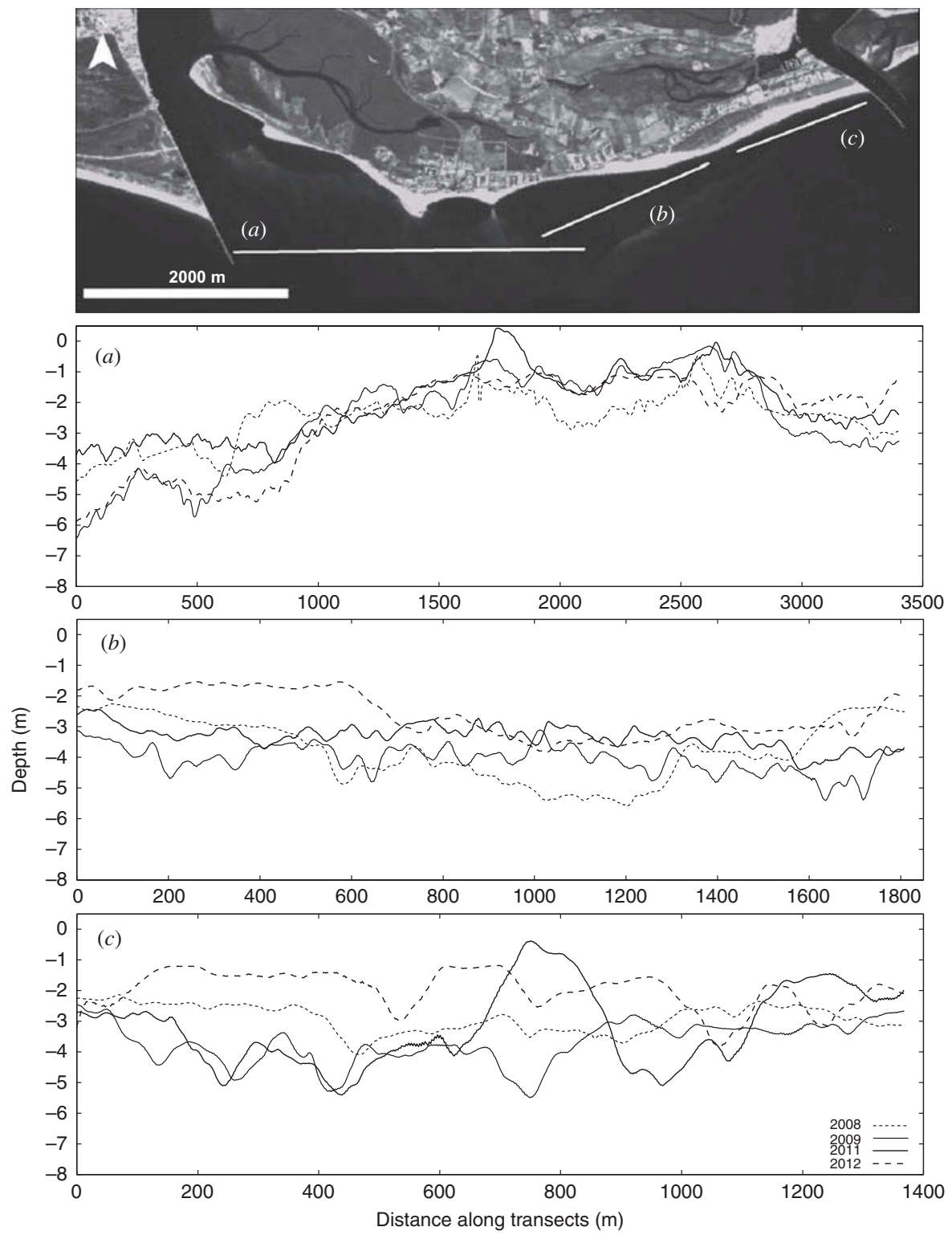

Figure 8. Temporal evolution of depth profiles along the three transect lines (running west to east) in the top figure: (a) Guadiana delta, (b) coast east of the delta, and (c) coast west of the Corrientes River. 
Figure 8 shows the depth profiles along three transects (orientated eastwards). The first transect runs across the Guadiana delta, and shows consistency among the extrapolated bathymetries in this area. The second runs parallel to the coast, in an accretion area east of the delta; the largest changes take place in 2011-2012 in its westmost third. Finally, the third transect runs along an area west of the Corrientes River, with patches rising and sinking alternatively in the images in Figure 7. These resemble in Figure 8 the sand-waves described by $\mathrm{Xu}$ et al. (2008) in a submarine canyon. It is also apparent there how the sand dune takes over the transect while approaching the coast in the period 20112012.

The possibility open to monitoring all these changes is very interesting from the point of view of coastal management, as these structures refract and focus the waves over different sectors of the Costa Ballena beach (east of the study area).

\section{Conclusion}

Results presented above show that optical bathymetry, using the empirical models studied, represents an alternative to direct sampling for submarine delta sandbar monitoring in an area with high geomorphologic activity. Furthermore, we have shown how to include older (and newer) images in order to study the historic evolution of the area geomorphology, without resorting to other lidar measurements.

In areas of waters shallower than $4 \mathrm{~m}$ in depth (where sediment dynamics is more dramatic), errors around $0.5 \mathrm{~m}$ can be obtained, as has been shown. This accuracy may be enough in areas like the Guadiana estuary mouth, where sandbars, having vertical dimensions of 1-2 m, are created and destroyed with high frequency. The current trend of the sandy features linked to the submarine delta is to move towards the shoreline within the study area. The problems associated with their interaction with the waves (shoreline erosion, silt sedimentation in sheltered areas, etc.) justify our approach for monitoring them. This approach, despite its simplicity, is effective as has been shown in the change series calculated, where known features of actual dynamics have been identified. To our knowledge, this would be the first step towards short-term bathymetry monitoring based on optical satellite remote sensing.

\section{Acknowledgements}

The authors thank Miguel Fernández and Elena Couñago for their help with the cartography, and the two reviewers for their insightful observations.

\section{Funding}

The authors acknowledge financial support from project CSO2010-15807 of Spanish Ministerio de Ciencia e Innovación supported by European Regional Development Fund (ERDF), and project P10-RNM-6207 of Consejería de Innovación, Ciencia y Empresa, Junta de Andalucía (Spain), during the development of this work.

\section{Notes}

1. Agencia de Medio Ambiente y Agua de Andalucia: public agency, attached to the Agriculture, Fisheries and Environment Department of Andalusia Regional Government.

2. This image showed a geometric correction artifact on its lower left region. It has been handcorrected in order to display the results. 
3. European Space Agency, Basic ERS \& Envisat (A) ATSR and Meris Toolbox (BEAM), https:// earth.esa.int/web/guest/software-tools.

4. Language and environment for statistical computing: http://www.R-project.org.

\section{References}

Adler-Golden, S. M., P. K. Acharya, A. Berk, M. W. Matthew, and D. Gorodetzky. 2005. "Remote Bathymetry of the Littoral Zone From AVIRIS, LASH, and QUIckBIRD Imagery." IEEE Transactions on Geoscience and Remote Sensing 43 (2): 337-347. doi:10.1109/TGRS. 2004.841246.

Akaike, H. 1974. "A New Look at the Statistical Model Identification." Automatic Control, IEEE Transactions on Automatic Control AC-19 (6): 716-723. doi:10.1109/TAC.1974.1100705.

Bagheri, S., M. Stein, and R. Dios. 1998. "Utility of Hyperspectral Data for Bathymetric Mapping in a Turbid Estuary." International Journal of Remote Sensing 19 (6): 1179-1188. doi:10.1080/ 014311698215676.

Basu, A., and S. Malhotra. 2002. "Error Detection of Bathymetry Data by Visualization Using GIS." ICES Journal of Marine Science 59 (1): 226-234. doi:10.1006/jmsc.2001.1147.

Benny, A. H., and G. J. Dawson. 1983. "Satellite Imagery as an Aid to Bathymetric Charting in the Red Sea." Cartographic Journal 20 (1): 12. doi:10.1179/000870483787313209.

Bierwirth, P. N., T. J. Lee, and R. V. Burne. 1993. "Shallow Sea-Floor Reflectance and Water Depth Derived by Unmixing Multispectral Imagery." Photogrammetric Engineering and Remote Sensing 59 (3): 331-338.

Bramante, J. F., D. K. Raju, and T. M. Sin. 2013. "Multispectral Derivation of Bathymetry in Singapore's Shallow, Turbid Waters." International Journal of Remote Sensing 34 (6): 37-41. doi: $10.1080 / 01431161.2012 .734934$.

Chust, G., M. Grande, I. Galparsoro, A. Uriarte, and A. Borja. 2010. "Capabilities of the Bathymetric Hawk Eye LiDAR for Coastal Habitat Mapping: A Case Study Within a Basque Estuary." Estuarine, Coastal and Shelf Science 89 (3): 200-213. doi:10.1016/j.ecss.2010.07.002.

Chust, G., P. Liria, I. Galparsoro, M. Marcos, A. Caballero, and R. Castro. 2009. "Human Impacts Overwhelm the Effects of Sea-Level Rise on Basque Coastal Habitats (N Spain) Between 1954 and 2004." Estuarine, Coastal and Shelf Science 84 (4): 453-462. doi:10.1016/j. ecss.2009.07.010.

Clark, J. R. 1996. Coastal Zone Management Handbook. Boca Raton, FL: CRC-Press.

Collet, C., J.-N. Provost, P. Rostaing, P. Pérez, and P. Bouthemy. 2000. "SPOT Satellite Data Analysis for Bathymetric Mapping." In Proceedings of the 2000 International Conference on Image Processing, vol. 3, 464-467. Vancouver, BC, September 10-13.

Conger, C. L., E. J. Hochberg, C. H. Fletcher, and M. J. Atkinson. 2006. "Decorrelating Remote Sensing Color Bands from Bathymetry in Optically Shallow Waters." IEEE Transactions on Geoscience and Remote Sensing 44 (6): 1655-1660. doi:10.1109/TGRS.2006.870405.

Costanza, R., and J. Farley. 2007. "Ecological Economics of Coastal Disasters: Introduction to the Special Issue.” Ecological Economics 63 (2-3): 249-253. doi:10.1016/j.ecolecon.2007.03.002.

Densham, M. P. 2005. "Bathymetric Mapping with Quickbird Data." PhD diss., Naval Postgraduate School, Monterrrey, CA.

Dierssen, H. M., R. C. Zimmerman, R. A. Leathers, T. V. Downes, and C. O. Davis. 2003. "Ocean Color Remote Sensing of Seagrass and Bathymetry in the Bahamas Banks by High Resolution Airborne Imagery." Limnology and Oceanography 48: 444-455. doi:10.4319/ 10.2003.48.1 part 2.0444.

Doxani, G., K. Karantzalos, and M. Tsakiri-Strati. 2012. "Monitoring Urban Changes Based on Scale-Space Filtering and Object-Oriented Classification." International Journal of Applied Earth Observation and Geoinformation 15: 38-48. doi:10.1016/j.jag.2011.07.002.

Finkl, C. W., L. Benedet, and J. L. Andrews. 2005. "Interpretation of Seabed Geomorphology Based on Spatial Analysis of High-Density Airborne Laser Bathymetry." Journal of Coastal Research 213: 501-514. doi:10.2112/05-756A.1.

Gao, J. 2009. "Bathymetric Mapping By Means Of Remote Sensing: Methods, Accuracy and Limitations." Progress in Physical Geography 33 (1): 103-116. doi:10.1177/ 0309133309105657.

Garlan, T. 1989. Spatial Cartography of the Coralline Coast: Topography and Bathymetry. Brest: Service Hydrographique et Oceanographique de la Marine, Ministere de la Defense. 
Morales, J. A. 1997. "Evolution and Facies Architecture of the Mesotidal Guadiana River Delta (S. W. Spain-Portugal)." Marine Geology 138 (1-2): 127-148. doi:10.1016/S0025-3227(97) 00009-1.

Mumby, P. J., E. P. Green, A. J. Edwards, and C. D. Clark. 1999. "The Cost-Effectiveness of Remote Sensing for Tropical Coastal Resources Assessment and Management." Journal of Environmental Management 55: 157-166. doi:10.1006/jema.1998.0255.

Muslim, A. M., and M. Foody. 2008. "DEM and Bathymetry Estimation for Mapping a TideCoordinated Shoreline from Fine Spatial Resolution Satellite Sensor Imagery." International Journal of Remote Sensing 29 (15): 4515-4536. doi:10.1080/01431160802029685.

Newton, A., and J. Icely. 2008. "Land Ocean Interactions in the Coastal Zone, LOICZ: Lessons From Banda Aceh, Atlantis, and Canute.” Estuarine, Coastal and Shelf Science 77 (2): 181184. doi:10.1016/j.ecss.2007.09.016.

Nishida, T., M. Mohri, K. Itoh, and J. Nakagome. 2001. "Study of Bathymetry Effects on the Nominal Hooking Rates of Yellowfin Tuna (Thunnus Albacares) and Bigeye Tuna (Thunnus Obesus) Exploited by the Japanese Tuna Longline Fisheries." IOTC Proceedings 4 (4): 191-206.

Ojeda, J., L. Borgniet, A. M. Pérez-Romero, and J. F. Loder. 2002. "Monitoring Morphological Changes Along the Coast of Huelva (SW Spain) Using Soft-Copy Photogrammetry and GIS." Journal of Coastal Conservation 8: 69-76. doi:10.1652/1400-0350(2002)008[0069:MMCATC] 2.0.CO;2.

Philpot, W. D. 1989. "Bathymetric Mapping with Passive Multispectral Imagery." Applied Optics 28 (8): 1569. doi:10.1364/AO.28.001569.

Prandle, D. 2006. "Dynamical Controls on Estuarine Bathymetry: Assessment Against UK Database." Estuarine, Coastal and Shelf Science 68 (1-2): 282-288. doi:10.1016/j. ecss.2006.02.009.

Provost, J.-N., C. Collet, P. Pérez, and P. Bouthemy. 1999. "A Hierarchical Unsupervised Multispectral Model to Segment SPOT Images for Ocean Cartography." In Proceedings of the 1999 International Conference on Image Processing, 1999. ICIP 99, Vol. 1, 333-337, Kobe, October 24-26.

Provost, J. N., C. Collet, P. Rostaing, P. Pérez, and P. Bouthemy. 2004. "Hierarchical Markovian Segmentation of Multispectral Images for the Reconstruction of Water Depth Maps." Computer Vision and Image Understanding 93 (2): 155-174. doi:10.1016/j.cviu.2003.07.004.

Sánchez-Carnero, N., S. Aceña, D. Rodríguez-Pérez, E. Couñago, P. Fraile, and J. Freire. 2012. "Fast and Low-Cost Method for VBES Bathymetry Generation in Coastal Areas." Estuarine, Coastal and Shelf Science 114: 175-182. doi:10.1016/j.ecss.2012.08.018.

Stocks, K. I., G. W. Boehlert, and J. F. Dower. 2004. "Towards an International Field Program on Seamounts Within the Census of Marine Life." Archive of Fishery and Marine Research 51: 320-327.

Stumpf, R. P., K. Holderied, and M. Sinclair. 2003. "Determination of Water Depth with HighResolution Satellite Imagery over Variable Bottom Types." Limnology and Oceanography 48 (1-2): 547-556. doi:10.4319/lo.2003.48.1_part_2.0547

Sutherland, J., D. J. R. Walstra, T. J. Chesher, L. C. van Rijn, and H. N. Southgate. 2004. "Evaluation of Coastal Area Modelling Systems at an Estuary Mouth." Coastal Engineering 51 (2): 119-142. doi:10.1016/j.coastaleng.2003.12.003.

Van Rijn, L. C., D. J. R. Walstra, B. Grasmeijer, J. Sutherland, S. Pan, and J. P. Sierra. 2003. "The Predictability of Cross-Shore Bed Evolution of Sandy Beaches at the Time Scale of Storms and Seasons Using Process-Based Profile Models." Coastal Engineering 47 (3): 295-327. doi:10.1016/S0378-3839(02)00120-5.

Wedding, L. M., A. M. Friedlander, M. McGranaghan, R. S. Yost, and M. E. Monaco. 2008. "Using Bathymetric Lidar to Define Nearshore Benthic Habitat Complexity: Implications for Management of Reef Fish Assemblages in Hawaii." Remote Sensing of Environment 112 (11): 4159-4165. doi:10.1016/j.rse.2008.01.025.

Xu, J. P., F. L. Wong, R. Kvitek, D. P. Smith, and C. K. Paull. 2008. "Sandwave Migration in Monterey Submarine Canyon, Central California." Marine Geology 248: 193-212.

Zhang, Y., J. Gao, and Y. Gu. 2011. "A Simple Method for Mapping Bathymetry Over Turbid Coastal Waters from MODIS Data: Possibilities and Limitations." International Journal of Remote Sensing 32 (22): 7575-7590. doi:10.1080/01431161.2010.524903. 